\title{
USABILIDADE DA TELEMEDICINA COMO UMA PLATAFORMA DE ENSINO COLABORATIVO PARA ESTUDANTES DE MEDICINA
}

\author{
Usability of Telemedicine as a Collaborative Learning Platform Tool for Medical Students
}

Ana Cláudia Costa Arantes ${ }^{1}$; Aline Teodósio dos Santos Cardozo'; Leonardo Frajhof²; Soeli Teresinha Fiorini ${ }^{3}$

Resumo Objetivos: Uma das características fundamentais da tecnologia da informação é a versatilidade. Dessa forma é possível elaborar programas educacionais utilizando esse tipo de tecnologia, mais especificamente a telemedicina. Este artigo relata o desenvolvimento de duas ferramentas de ensino-aprendizagem intituladas "Youknow" e "SANA" e descreve a experiência de professores e alunos de medicina com essas novas metodologias de ensino. Materiais e métodos: Realizada na Universidade Federal do Estado do Rio de Janeiro- UNIRIO, no Hospital Universitário Gaffrée Guinle, a experiência com as ferramentas contou com a participação das alunas do $3^{\circ}$ ano de graduação de medicina, cursando a disciplina de clinica médica, que por sua vez define a entrada dos estudantes na rotina hospitalar. Resultados: As novas tecnologias da informação descritas ao longo do artigo buscaram o diálogo aberto entre professor-aluno e comunidade medica, desenvolvendo uma forma colaborativa de ensinoaprendizagem entre docentes e discentes. Conclusão: A partir dessa experiência considerou se viável a utilização da telemedicina como base para criar ferramentas de ensino-aprendizagem para alunos e professores da graduação de medicina, pois além de afastar da tradicional metodologia de ensino, arcaica e hierárquica, fomenta a autonomia dos alunos e incentiva as relações inter e intrapessoais entre alunos, médicos, professores e comunidade.

Palavras-chave: Telemedicina, Usabilidade, Colaboração, e-health, Ensino-Aprendizagem

Abstract Aims: One of the fundamental characteristics of information technology is its versatility. Because of that, it is possible to develop educational programs using this type of technology, specifically telemedicine. This article reports the development of two teaching and learning tools entitled "Youknow" and "SANA" and describes the experience of teachers and medical students in these new teaching methodologies. Materials and methods: Held at the Federal University of the State of Rio de Janeiro - UNIRIO, in the University Hospital Gaffrée Guinle, this experience was leaded by 3rd year students of medical school, attending the course of medical practice, which in turn defines the entry of students in the hospital routine. Results: The new information technologies described throughout the article sought free dialogue between teacher-student and medical community, developing a collaborative form of teaching and learning among teachers and students. Conclusion: From this experience, it was considered feasible to use telemedicine as a basis to create teaching and learning tools for students and teachers of undergraduate medicine, as well as away from the traditional teaching methodology, archaic and hierarchical, fosters student's autonomy and encourages inter and intrapersonal relationships among students, doctors, teachers and community.

Keywords: eHealth, Collaboration, Learning, Usability, Telemedicine

1. Acadêmico de Medicina - UNIRIO; 2. Médico e Professor de clinica médica - UNIRIO; 3. Pesquisadora do LES - Laboratório de engenharia de software - PUC RIO. 


\section{Introdução}

No atual cenário do mundo globalizado, barreiras geográficas deixam de ser empecilhos para troca de informações. A partir da revolução digital, principalmente em meados da década de 90 , nota-se um aumento significativo da demanda de novos serviços de tecnologia e, consequentemente, maior desenvolvimento de novas ferramentas de informação, facilitando a rotina do usuário. PCs (private computers), internet, celulares, redes sociais, tablets e smartphones são apenas alguns tipos de utilitários que foram criados e estão em constante desenvolvimento e aperfeiçoamento.

Aliás, é característica relevante desses recursos, a capacidade de proporcionar dinamismo e rapidez no processo de troca de dados. Outro aspecto interessante é que a maior parte dos usuários dessas ferramentas é composta por jovens, muitos deles, ainda em processo de formação acadêmica. Sendo assim, cada vez mais, busca-se integrar os adventos tecnológicos a diversas áreas de atuação, como a educação e a medicina.

Segundo o Instituto Brasileiro de Geografia e Estatística (IBGE) recentemente dados relativos ao uso dos telefones celulares no Brasil mostram que de 2005 a 2011 houve um crescimento de 107,2\%. Em 2011, eram 115,4 milhões os donos brasileiros de celular, o que representa $69,1 \%$ da população com mais de dez anos. Sete anos antes, o número de consumidores era de 55,7 milhões de pessoas. Outro dado interessante apontado na pesquisa TIC Domicílios realizada em 2012 (CETIC) aponta que há crescimento na utilização da internet a partir dos dispositivos móveis.

$\mathrm{O}$ artigo da revista Telemedicine and e-Health também descreve, entre outros, que enviar mensagens de texto de telefone celular tem sido útil para os pacientes reduzirem as faltas aos compromissos médicos e para permanecerem em contato com o seu médico para acompanhamento e esclarecimento de dúvidas. Quando se fala na com- paração com a tecnologia de computador, a posse e o uso de telefones celulares é maior entre as pessoas de baixo nível socioeconômico, reduzindo a exclusão social. Além disso, mais pacientes possuem e estão dispostos a utilizar as tecnologias móveis para a gestão da doença crônica.

O site "Hands On Telehealth" relata pesquisas que mostram como os médicos estão usando a tecnologia móvel; $55 \%$ dos médicos estão usando aplicativos móveis e esta utilização é um fator-chave de adoção na área de telessaúde, pois sentem-se pelo menos confortáveis com a tecnologia; $50 \%$ dos médicos fazem acesso ao YouTube para fins médicos e $60 \%$ dos médicos estão usando as plataformas sociais, por exemplo Sermo, Medscape, Linkedln e Facebook, para acompanhar o que os colegas estão discutindo ou dizendo.

Sendo assim, percebe-se que cada vez mais as tecnologias móveis serão utilizadas no setor da saúde.

Nesse contexto, na Escola de Medicina e Cirurgia da Universidade Federal do Estado do Rio de Janeiro - UNIRIO -, alunas do quinto período do curso de medicina, em conjunto com o Laboratório de Engenharia de Software - LES da PUC-RIO - vivenciaram a interação da tecnologia aqui representada pela telemedicina e uso de tablets e smartphones, com a medicina durante o processo de construção de aprendizado.

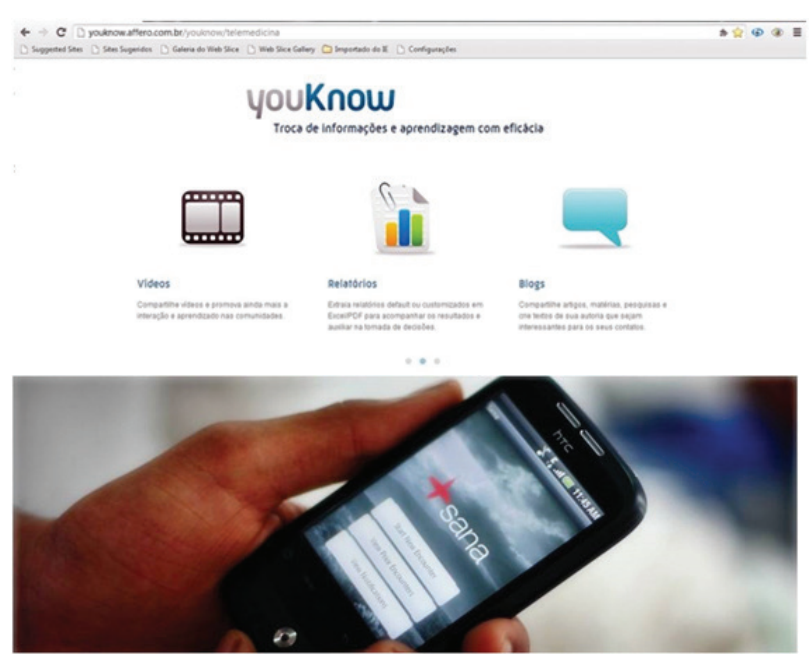

Figuras 1 e 2. Imagem capturada da página principal da rede social YouKnow e página inicial do aplicativo SANA 


\section{Objetivos}

Relatar a experiência das estudantes de medicina ao longo do seu primeiro ano de prática no hospital universitário, com as seguintes ferramentas de tecnologia da informação: rede social ("You Know") e aplicativo Android ("Sana").

Discutir sobre a importância do desenvolvimento de novas ferramentas no processo de ensino-aprendizagem para estudantes de graduação de medicina

\section{Metodologia}

Primeiramente, foi utilizado o software "Youknow", desenvolvido pela empresa Affero. O YouKnow é uma plataforma baseada na web para organização de redes sociais entre usuários que discutem um determinado tema de estudo. O principal objetivo da ferramenta é promover o aprendizado de maneira colaborativa entre os participantes. Essa tem como enfoque a interação entre o modelo tradicional de ensino e processos baseados na colaboração entre pessoas. Durante os meses de Agosto a Novembro do ano de 2011, através de encontros semanais, alunas do quinto período do curso de medicina da Universidade Federal do Estado do Rio de Janeiro (UNIRIO), utilizaram esse software como forma de aprendizado durante a realização da disciplina Clínica Médica I. Essa matéria proporciona a iniciação do estudante na rotina hospitalar, cujo desenvolvimento é baseado na análise de casos clínicos em ambulatórios tutoriados por médicos e especialistas do Hospital Universitário Gaffrée e Guinle. A experiência com a ferramenta consistiu no estudo de caso do prontuário de um paciente atendido pelo médico/professor. Para o desenvolvimento desse estudo, o professor fornecia gradativamente informações sobre o paciente às alunas. Dessa forma, as alunas puderam desenvolver análises associadas ao conteúdo teórico e prático aprendido em aulas presenciais na disciplina de Clínica Médica. Inicialmente, foi criada no ambiente virtual, uma comunidade denominada Clinica Médica. Nesse espaço, as alunas publicaram as informações contidas no prontuário, dúvidas, pesquisas de materiais e artigos na literatura científica, diagnósticos diferenciais e, finalmente, o diagnóstico do paciente confirmado pelo médico/professor. Essas informações foram organizadas a partir dos itens previamente estabelecidos na comunidade, tais como: lição aprendida, melhores práticas, artigo, fórum, galeria de imagens, vídeos, entrevista e coluna.

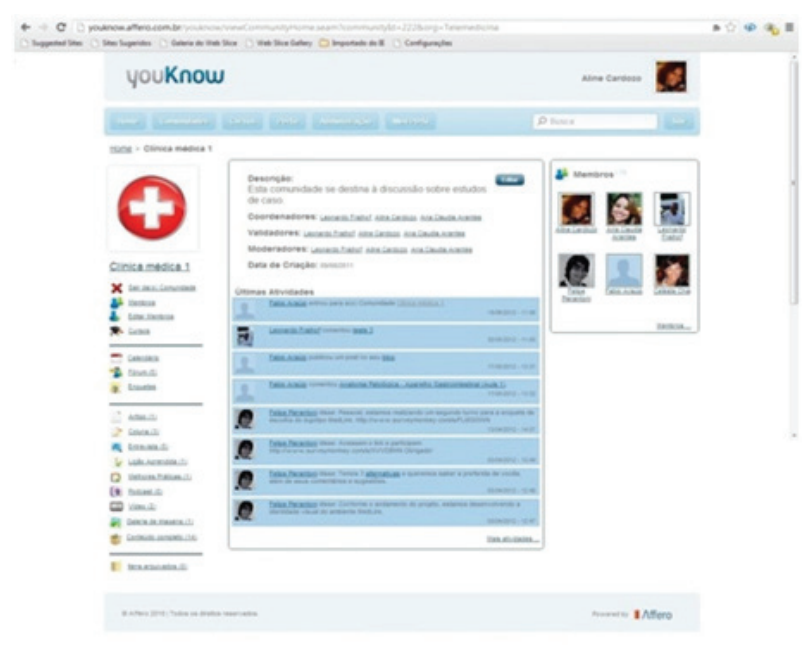

Figura 3. Imagem capturada da comunidade "Clinica Médica I" onde foi desenvolvido o trabalho com as alunas.

Posteriormente, utilizou-se o aplicativo Sana desenvolvido pela MIT (Massachusetts Institute of Technology). O Sana oferece um sistema de coleta de dados que pode ser utilizado por profissionais da área de saúde, através de aparelhos móveis. Nesse trabalho, os aparelhos utilizados foram os tablets Motorola Xoom e Ipad 2, além de celulares Samsung Galaxy. Em Janeiro de 2012, iniciou-se a fase de teste do Sana: as alunas elaboraram um modelo de ficha composta por perguntas objetivas formando uma anamnese dirigida que tinha por objetivo ser preenchida pelas alunas com informações dos pacientes. Em março de 2012, com o retorno das atividades acadêmicas, as alunas iniciaram a utilização do Sana no ambulatório de Clínica Médica (CM) do Hospital Universitário Gaffrée e Guinle 
(HUGG), sob orientação do professor e médico Leonardo Frajhof. A coleta de dados ocorreu da seguinte forma: semanalmente, sempre às terças-feiras, os pacientes eram conduzidos até a sala da Telemedicina, onde seriam entrevistados individualmente pelas estudantes de medicina. Ao final dessa etapa, cada indivíduo era encaminhado até a sala do ambulatório, onde seria atendido pelo médico. Após a realização de todas as entrevistas, as fichas eram impressas e entregues ao mestre, ao mesmo tempo em que os dados eram enviados a um servidor chamado OpenMRS. Essa página funciona como um banco de dados e possibilita que o médico, desde que cadastrado previamente, tenha acesso às informações de seus pacientes, por meio de tablet, laptop, celular ou computador.
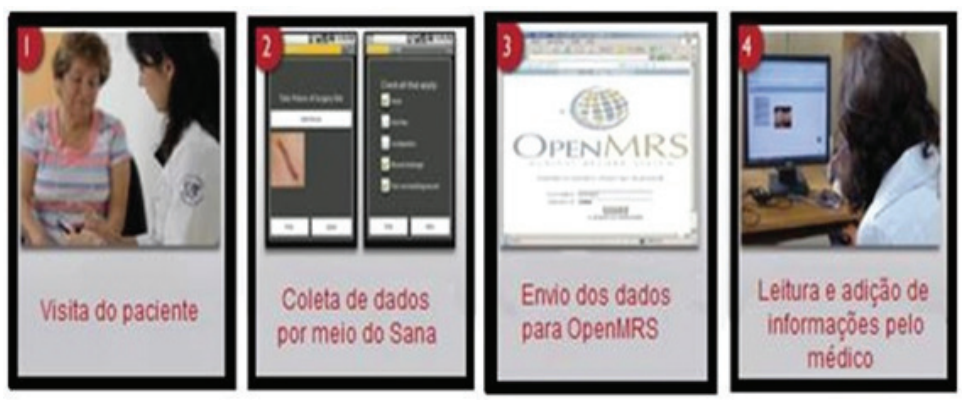

Figura 4. Montagem demonstrando a sequência de eventos ocorrida ao utilizar o aplicativo SANA.

\section{Resultados}

Em relação ao YouKnow, os alunos escolheram o item Lição aprendida para iniciar a atividade de publicação do conteúdo da disciplina. Essa escolha foi motivada pelo fato de esse item apresentar perguntas previamente cadastradas que direcionaram mais precisamente a apresentação do caso estudado pelos alunos. Após a anamnese do paciente ter sido publicada nesse item, contendo os vários diagnósticos diferenciais e uma imagem relacionada ao tema, o professor utilizou o item "Melhores Práticas" para divulgar os exames que o paciente já havia realizado: exame prébiópsia de pâncreas (tomografia e colangioressonância). Ao mesmo tempo, um artigo científico no item Artigo intitulado
“Diabetes mellitus e carcinoma ductal de pâncreas"1 (Maria Adelaide A. Pereira, Serviço de Endocrinologia e Metabologia, Hospital das Clínicas da FMUSP, São Paulo, SP) foi publicado pelos alunos, uma vez considerado pertinente e semelhante ao caso estudado. Durante todo o processo de análise do caso, as dúvidas que surgiam eram publicadas no item Fórum, com o objetivo de serem respondidas pelo professor ou até mesmo pelos próprios alunos. Em um dos encontros semanais, o professor divulgou os exames complementares realizados no paciente no item Galeria de Imagens, bem como dois filmes em streaming: Endoscopia Digestiva Alta e Colangiografia, no item Vídeos. No item Entrevista, foram postados laudos das imagens e exames laboratoriais. Também foi utilizado esse item para transcrever o prontuário do paciente. A partir de todas essas informações liberadas pelo professor e através de pesquisas em livros de consulta de Medicina Interna, os alunos conseguiram diagnosticar o caso. Após a confirmação do diagnóstico pelo médico/professor, o mesmo foi publicado no item Lição Aprendida acompanhado de um breve resumo sobre a doença. No item Coluna, foi publicada uma apresentação em PowerPoint sobre o diagnóstico do paciente. Finalmente, os alunos criaram links entre as informações postadas nos itens por meio do subitem "Este item está relacionado a", uma vez que os assuntos e informações se relacionavam. Todas as ferramentas de aprendizagem foram exercitadas pelos alunos, exceto o item podcast pela ausência de material adequado para a realização de gravações de áudio.

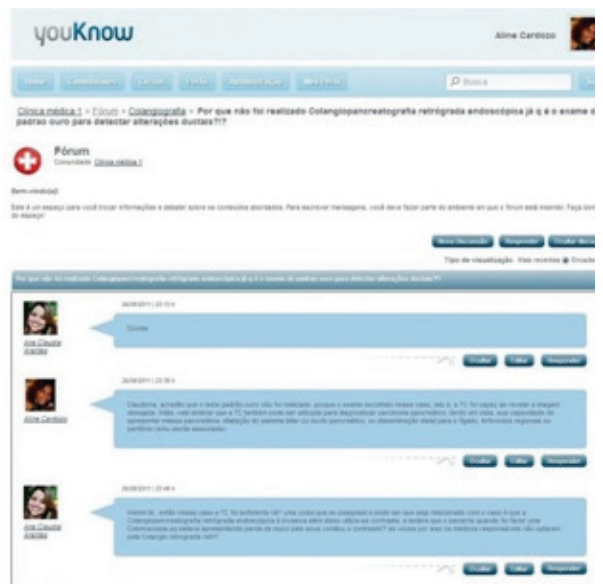

Figura 5. Imagem capturada do item "fórum" onde houve a discussão e troca de informações com perguntas e respostas entre participantes 
Já no Sana, durante a fase de teste, diversos questionários foram respondidos, a fim de verificar se o envio desses para o OpenMRS aconteceria adequadamente. Nesse momento, verificou-se que as fichas fornecidas pelo aplicativo não se enquadravam de forma satisfatória à realidade de um ambulatório de clínica médica. As fichas fornecidas pelo aplicativo são específicas, enquanto que as comorbidades, queixas e patologias dos pacientes que frequentam esse tipo de ambulatório são as mais diversas. Sendo assim, as alunas de medicina desenvolveram uma ficha de atendimento que enquadrasse de forma satisfatória aquele ambiente. Posteriormente, esse questionário foi inserido no aplicativo e aplicado nos pacientes ambulatoriais. A ficha continha quesitos essenciais para uma pré-consulta tais como: identificação, queixa principal, comorbidades, medicamentos em uso, pressão arterial, frequência cardíaca, frequência respiratória, temperatura corporal, glicose capilar, direcionamento, exames e observações. Dessa forma, observa-se que foi necessário que tais estudantes recorressem a conhecimentos prévios, principalmente, da disciplina de semiologia, adquiridos por meio de leitura ou dentro de sala de aula, para que pudessem confeccionar as fichas. No período compreendido entre março e maio de 2012, foram coletadas ao todo 136 fichas. Semanalmente, os pacientes que frequentavam o ambulatório de Clínica Médica no qual se encontrava o médico e professor Leonardo Frajhof no HUGG (Hospital Universitário Gaffrée e Guinle) eram entrevistados por tais alunas. Nesse instante, mais uma vez, as alunas se viram na necessidade de pôr em prática não apenas os conhecimentos obtidos, principalmente, através das disciplinas de Clínica Médica e semiologia, já que teriam que realizar uma anamnese e um exame físico, como também se depararam com a questão da relação médico-paciente. Inicialmente, deve-se dizer que após quase 1 mês de utilização do Sana, essas alunas já verificavam que esse tipo de atividade havia melhorado o desempenho destas durante a anamnese e o exame físico, proporcionando mais segurança e desenvoltura ao lidar com o paciente. Vale lembrar que o médico/professor estava sempre presente, orientando e avaliando o desempenho dessas alunas como também tirando as dúvidas dessas estudantes, quando solicitado. Além disso, o programa funcionou como um verdadeiro facilitador na coleta de informações, otimizando esse processo. Aliás, nota-se inclusive uma maior agilidade durante o registro de dados em tais aparelhos, talvez, devido a um maior entrosamento entre as alunas e tablets/smartphones.

Vale lembrar que o uso dos aparelhos eletrônicos fornecidos durante o projeto não se restringiu apenas ao YouKnow e ao Sana. Eles foram utilizados também dentro e fora da sala de aula. As informações fornecidas pelos professores durante as aulas foram anotadas através deles. Aliás, o teclado touch presente nesses aparelhos oferece um pouco de dificuldade em um contato inicial, pois é necessário certo grau de entrosamento com ele, para que a digitação seja mais ágil e eficiente. No entanto, após esse período de adaptação, o registro das anotações ocorreu de modo bem mais eficaz do que o secular modelo de escrita. Outro aspecto relevante, é que, muitas vezes, os professores encaminham as aulas por e-mail em formato "pdf," "ppt" ou "doc". Nem todos os tablets e celulares possuem programas que possibilitem a leitura desses documentos, tampouco a composição de textos, por exemplo. Dessa forma, é necessário que o usuário de tais aparelhos conheça ou seja capaz de buscar aplicativos ou programas compatíveis com tais formatos, a fim de que possa ler ou produzir textos sem problemas. Além disso, tais aparelhos dispõem de um sistema Android que, uma vez conectado à internet, permite o download dos mais diversos aplicativos. Cabe ressaltar que embora muitos deles estejam relacionados a jogos e redes sociais, existem também diversos relacionados à medicina e à educação como Medscape, 
Epocrates, ECG Handbook, Vacinas Brasil e Auscultation Primer. Sendo assim, por meio destes, foi possível testar e atualizar conhecimentos, bem como as informações transmitidas em sala de aula, de maneira dinâmica e interativa.

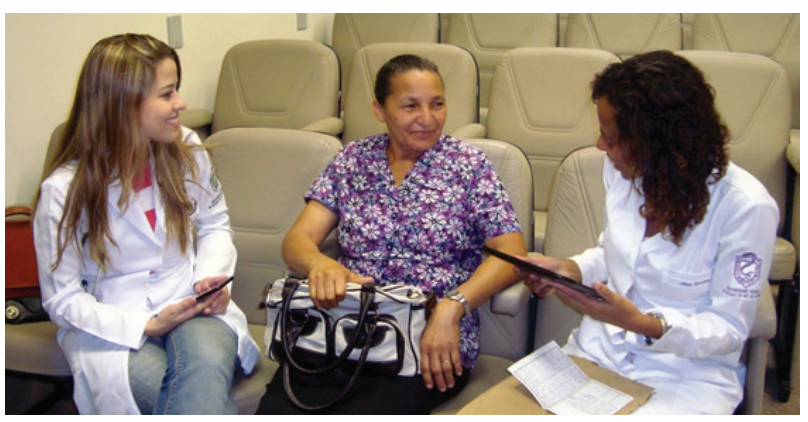

Figura 6. Alunas de medicina coletando dados da paciente através do aplicativo SANA.

\section{Discussão}

No presente estudo, nota-se que o processo de ensinoaprendizagem aqui empregado desconstrói o tradicional modelo de ensino, no qual o aluno é apenas um ouvinte do conteúdo transmitido pelo professor. Nessa nova forma de metodologia, as estudantes tiveram a oportunidade de expor seus conhecimentos e dialogar com seus orientadores. Além disso, atuaram ativamente durante o processo de formação e fixação de informações, já que lhes coube buscar o conteúdo necessário em anotações de aula, e outras fontes como livros didáticos e artigos, para confecção das fichas, no caso do aplicativo Sana, e da confecção de diagnósticos diferenciais no caso da rede social Youknow.

Tendo em vista a dificuldade da formulação diagnóstica, a discussão colaborativa entre os usuários foi outro aspecto relevante ocorrido nesse estudo. Inicialmente, por reunir as várias experiências profissionais de cada participante envolvido, facilitando e enriquecendo o processo rumo à elaboração das hipóteses diagnósticas. Posteriormente, por respeitar o tempo de aprendizagem de cada um, uma vez que não há prazo estipulado para que os alunos atinjam o objetivo desejado, diferentemente do que ocorre nas salas de aulas. Desse modo, todos terão maiores chances de concluírem com êxito a meta traçada por seu orientador.

De acordo com a avaliação das alunas, um dos fatores que influenciou no resultado positivo da utilização das ferramentas foi a usabilidade e praticidade de seus acessos, feito através de computadores e dispositivos móveis, ferramentas essas contemporâneas, pertinentes à geração em que os alunos estão inseridos e, por isso, apresentam facilidade em dominá-las.

\section{Conclusão}

As alunas, assim como o professor do estudo de caso, fizeram uma avaliação positiva do uso das ferramentas Youknow e Sana para o processo de ensino-aprendizagem na disciplina de Clinica Médica I. Considerou-se de extrema importância a participação ativa das alunas durante o processo de pesquisa do diagnóstico do caso analisado na experiência com a rede social Youknow, e durante a coleta de dados dos pacientes através do uso do Sana.

Durante a experiência com o uso da rede social, além do comportamento pró-ativo das alunas, expressando suas opiniões e discutindo com profissionais experientes, as mesmas aprenderam a coletar dados bibliográficos e analisá-los criticamente. Dada a complexidade da pesquisa de diagnóstico em clínica médica, a discussão colaborativa entre os usuários permitiu compreender que a busca de outras fontes faz-se necessária. Além disso, a discussão interativa permitiu às alunas um tempo de maturação maior para a formulação do diagnóstico, o que muitas vezes não é possível em aulas presenciais, dada a restrição temporal das mesmas. Sabe-se que o tempo de reflexão dos estudantes para a formulação do diagnóstico é individual e, portanto, variável. Sendo assim, a ferramenta online possibilita a maturação de ideias e reflexão sobre os casos em qualquer hora, e é um 
convite, portanto ao estudo autônomo, respeitando o tempo necessário para o aprendizado de cada um.

No caso do uso da ferramenta Sana, as alunas testaram seus conhecimentos adquiridos em aulas teóricas no ambiente hospitalar através da confecção das fichas e da coleta de dados. Por meio de uma pequena anamnese e exame físico básico, englobando aferição de pressão arterial, medição de frequência respiratória, cardíaca, glicose capilar e temperatura axilar, as estudantes tiveram a oportunidade de desenvolver e perceber mais de perto a importância de uma boa relação médico-paciente. Vale lembrar que todos esses aspectos levantados são de extrema relevância não só durante o processo de formação acadêmica, como também para a vida profissional.

A popularidade que as redes sociais (facebook, twitter, blogs) encontram na contemporaneidade também contribuiu para avaliação positiva do uso da ferramenta Youknow, uma vez que os alunos estão familiarizados com o uso delas. Esse tipo de rede social permite uma horizontalização das relações sociais e no caso da ferramenta Youknow, essa característica foi observada na relação entre professor/aluno/colaboradores.

Finalmente, considera-se viável a utilização de redes sociais e aplicativos eletrônicos como ferramentas de aprendizagem colaborativa em meios acadêmicos, pois fomenta a autonomia dos alunos, a participação ativa dos mesmos e a compreensão da complexidade que envolve os casos estudados. As relações inter e intrapessoais são também incentivadas nesse processo, sendo elas importantes para a formação do indivíduo atuante na sociedade.

\section{Referências}

1. Araújo, V.D.L.: O impacto das redes sociais no processo de ensino e aprendizagem. J. Anais eletrônicos. 3, 1-13 (2010)

2. Instituto Brasileiro de Geografia e Estatística - Dados de Pesquisa (IBGE). Disponível em: \&lt;http://migre.me/galEK\&gt;. Acesso em Novembro de 2013

3.http://www.handsontelehealth.com/past-issues/135-how-doctors-use-of-mobiletechnology-impacts-telehealth-infographic-and-insights. Acesso em Novembro de 2013

4. Santosh Krishna, Suzanne Austin Boren, Andrew Balas; Healthcare via Cell Phones: A Systematic Review, Mary Ann Liebert, Inc. • Vol. 15 No. 3 • April 2009 Telemedicine and e-Health

5. O'Reilly, T.: What is Web 2.0: Design Patterns and Business Models for the Next Generation of Software. Communications \&amp; Strategies. 1, 17 (007)

6. Pimentel, M., Fuks, H.: Sistemas Colaborativos. Elsevier, Rio de Janeiro (2011)

7. Youknow. http://www.eduweb.com.br/produtos-e--servicos/tecnologia/you-know (2012)

8. Cirilo, E., Nunes, I., Carvalho, D., Carvalho, G., Veiga, A., Lucena, C.: Engenharia de software em Telessaúde: aplicações e desafios. In: Gold Book, pp.371-404. 50th Scientific Congress of HUPE, Rio de Janeiro (2012)

9. Lucena, C.A.P., Mont'Alvão, C.R., Frajhof, L.: Collaborative learning platform in the field of telemedicine. IADIS International Journal on Computer Science and Information Systems, IADIS International Conference e-Health (2012)

10. Boto, C. O ensino tradicional e sua tradição: histórias e raízes. Jornal UNESP, São Paulo, n. 216, out. 2006. Disponível em: \&lt; http://www.unesp.br/aci/jornal/216/ supled.php\&gt; Acesso em: 30 jun 2013

11. MORAN, J. M. Como utilizar a Internet da educação. Revista Ciência da Informação, São Paulo, v. 26, n. 2, p. 146-153, mai./ago. 1997

12. Sana. Disponível em: \&lt;http://sana.mit.edu/\&gt; Acesso em: 30 jun 2013 (2013) 